\title{
The effects of interactions between intrinsic properties and network parameters on bilateral phasing in a reduced leech heartbeat system
}

\author{
Adam L Weaver \\ From The Twenty Third Annual Computational Neuroscience Meeting: CNS*2014 \\ Québec City, Canada. 26-31 July 2014
}

The leech heartbeat central pattern generator (CPG) consists of a network of heart interneurons (HN) that coordinate heart excitor (HE) motor neuron activity via inhibitory chemical synapses. Each segmental pair of HE's is connected to one another via electrical coupling. Depending on the segment, the pair of motor neurons in the living system is active across a wide range of phase differences from nearly in-phase to anti-phase [1]. Prior efforts to model this complete network have not quantitatively matched all contralateral phase values observed [2]. We have created a reduced network model in Simulink to explore parameters that contribute to these phase differences. This parameter search has been analyzed in MATLAB using the PANDORA toolbox [3].

In our network model, we implemented known neuronal properties and synaptic connections from a single segmental ganglion. The HN's were modeled as endogenous bursters as previously described with a network cycle period of $9.45 \pm 0.11 \mathrm{sec}$ [4]; in previous studies [5], the HE's were modeled as tonic firers. We varied three network parameters shown in Figure 1 in this study: phased delay of the right $\mathrm{HN}$ synaptic input $\left[\Phi_{S y n}\right]$, the maximum conductances of the inhibitory synapse $\left[g_{S y n}\right]$, and electrical coupling strength $\left[g_{\text {coup }}\right]$. We varied $\boldsymbol{\Phi}_{\text {Syn }}$ to emulate the variable timing of inhibition onto HE's in the full network of the living system. In addition, we varied the set of maximum conductances for the HE neurons in a linear fashion from classical $\mathrm{HE}$ (tonic firing) to $\mathrm{HN}$ (endogenous bursting) values to ascertain the role of intrinsic properties on phase-shifts.

This linear variation of HE properties from tonic firing towards endogenous bursting led to a step-wise phase

\footnotetext{
Correspondence: aweaver2@smcvt.edu

Department of Biology, Saint Michael's College, Colchester, VT 05439, USA
}

advance up to $\sim 0.10$ for both neurons. In-phase $\left(\Phi_{S y n}\right.$ : $0.0)$ and anti-phase (0.5) values of $\Phi_{S y n}$ produced expected HE phase differences. However, intermediate synaptic delays $(0.25,0.75)$ caused a reduction in phase differences as the two motor neurons pull towards one another due to their electrical coupling. The amount of phase difference reduction was directly impacted in a nonlinear manner by the intrinsic properties of these HE neurons. Duty cycle (burst duration / cycle period) was not significantly impacted by intrinsic properties. In

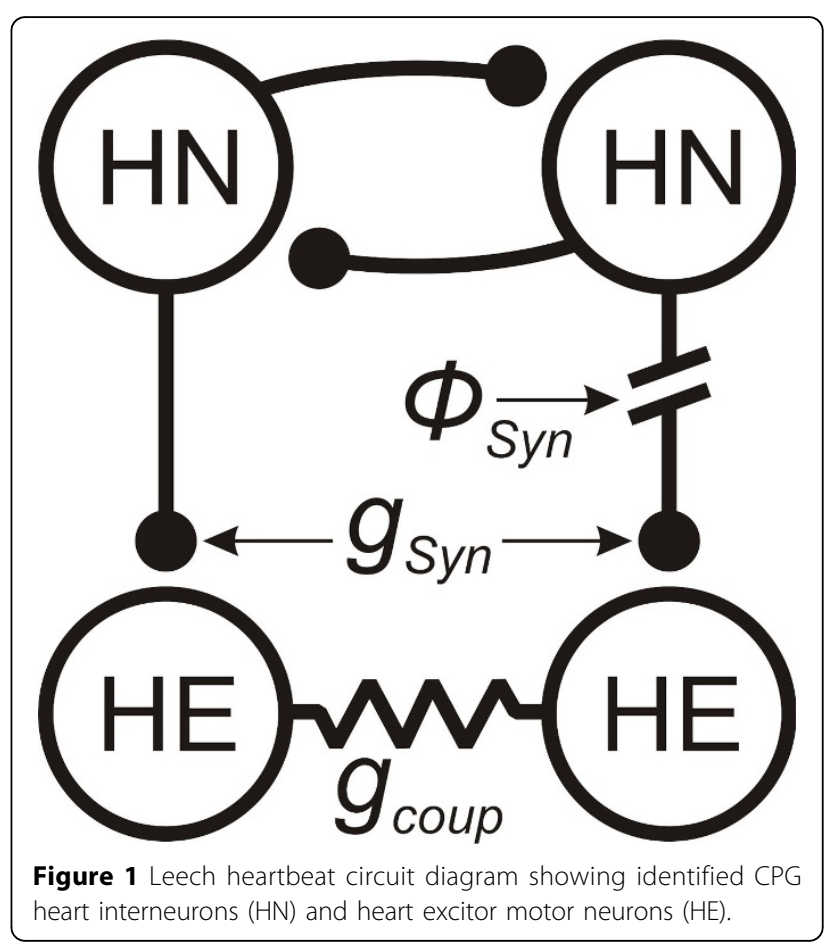


summary, increases in $\Phi_{S y n}$ led to non-monotonic changes in HE motor neuron contralateral phase differences.

Our search of parameter space continues to provide a foundation for understanding the mechanisms underlying variable phase differences in neuronal networks and reinforces the importance of interactions between endogenous properties and synaptic connections for producing functional motor patterns. The project described was supported by Vermont Genetics Network through an NIGMS (NIH) Institutional Development Award P20 GM103449.

Published: 21 July 2014

\section{References}

1. Norris BJ, Weaver AL, Wenning A, Garcia PS, Calabrese RL: A central pattern generator producing alternative outputs: phase relations of leech heart motor neurons with respect to premotor synaptic input. Journal of Neurophysiology 2007, 98(5):2983-2991.

2. Garcia PS, Wright TM, Cunningham IR, Calabrese RL: Using a model to assess the role of the spatiotemporal pattern of inhibitory input and intrasegmental electrical coupling in the intersegmental and side-to-side coordination of motor neurons by the leech heartbeat central pattern generator. Journal of Neurophysiology 2008, 100(3):1354-1371.

3. Günay C, Edgerton JR, Prinz AA, Jaeger D, Li S, Sangrey T: Database analysis of simulated and recorded electrophysiological datasets with PANDORA's toolbox. Neuroinformatics 2009, 7(2):93-111.

4. Weaver AL, Roffman RC, Norris BJ, Calabrese RL: A role for compromise: synaptic inhibition and electrical coupling interact to control phasing in the leech heartbeat CPG. Frontiers in Behavioral Neuroscience 2010, 4(38):1-17.

5. Weaver AL, Cowens KB: Compromise revisited: inhibitory synapse and electrical coupling effects on bilateral phasing in the leech heartbeat system. BMC Neuroscience 2012, 13(Suppl 1):1-2.

doi:10.1186/1471-2202-15-S1-P13

Cite this article as: Weaver: The effects of interactions between intrinsic properties and network parameters on bilateral phasing in a reduced leech heartbeat system. BMC Neuroscience 2014 15(Suppl 1):P13.

\section{Submit your next manuscript to BioMed Central and take full advantage of:}

- Convenient online submission

- Thorough peer review

- No space constraints or color figure charges

- Immediate publication on acceptance

- Inclusion in PubMed, CAS, Scopus and Google Scholar

- Research which is freely available for redistribution

Submit your manuscript at www.biomedcentral.com/submit
C Biomed Central 